\title{
PEMAHAMAN LINTAS BUDAYA BAGI PENDIDIK BAHASA MANDARIN
}

\author{
Ayu Trihardini, Aprilia Ruby Wikarti, Susi Andriani \\ Mandarin Education Department, Faculty of Languages and Arts, Universitas Negeri Jakarta \\ Campus A, DE Building 204, Jl. Rawamangun Muka Jakarta Timur
}

ayu.trihardini@unj.ac.id, apriliarubyw.s@unj.ac.id, susi.mandarinunj@unj.ac.id

\begin{abstract}
ABSTRAK
Seiring derasnya arus globalisasi, interaksi antar budaya merupakan hal yang tidak terelakkan. Ketika berinteraksi dengan orang yang berasal dari lingkungan budaya berbeda, diperlukan sikap toleransi, rasa saling memahami, saling menghargai dan berpikiran terbuka. Dengan demikian, seorang pendidik bahasa sangat perlu untuk memahami kebudayaan, adat istiadat dan kebiasaan bangsa penutur asli bahasa yang diajarkannya. Tulisan ini akan membahas mengenai pentingnya pemahaman lintas budaya bagi pendidik bahasa Mandarin, materi-materi budaya yang perlu dikuasai pendidik bahasa Mandarin, serta pemetaan kurikulum pengetahuan kebudayaan pada prodi kependidikan bahasa Mandarin di Indonesia.
\end{abstract}

Kata Kunci: Pemahaman Lintas Budaya, Pendidik, Bahasa Mandarin

\begin{abstract}
Along with the rapid flow of globalization, intercultural interactions are inevitable. When interacting with people from different cultural environments, tolerance, mutual understanding, mutual respect and open-mindedness are required. Thus, a language educator is very necessary to understand the culture and customs of a nation that uses the language it teaches. This paper will discuss the importance of cross-cultural understanding for Mandarin educators, cultural materials that need to be mastered by Mandarin educators, as well as a recommendation the mapping of curriculum of cultural knowledge in Mandarin education program in Indonesia.
\end{abstract}

Keywords: Cross Cultural Understanding, Educators, Mandarin Language 


\section{A. Pendahuluan}

Bahasa dan budaya mempunyai hubungan yang erat. Keeratan hubungan ini diungkapkan Sapir-Whorf dalam teori relativitas bahasa, bahwa kondisi dan kebudayaan seseorang sangat mempengaruhi bahasa yang digunakan dalam komunikasi sehari-hari. Hubungan erat antara bahasa dan budaya juga dipaparkan Koentjaraningrat (dalam Chaer, 2010) yang meyakini bahwa bahasa sebagai unsur pembentuk kebudayaan.

Suatu bahasa dipelajari utamanya agar dapat digunakan dalam berkomunikasi. Dalam komunikasi selain memerlukan keterampilan berbahasa dan pengetahuan mengenai unsur kebahasaan bahasa tersebut, juga membutuhkan pengetahuan lintas budaya.

Dewasa ini, pasar bebas barang, jasa, investasi dan tenaga kerja terdidik telah melewati batas regional masing-masing negara. Di kawasan ASEAN, ditandai dengan adanya Masyarakat Ekonomi ASEAN (MEA) dan di saat yang sama hadir era disrupsi teknologi revolusi industri 4.0. Klaus Schwab (2016) memaparkan, dalam konteks kehidupan sosial, paradigma revolusi industri 4.0 berpengaruh pada bagaimana cara kita bekerja, terutama berkomunikasi. Era baru ini menuntut kombinasi berbagai kemampuan yang berbeda dengan yang selama ini diberikan oleh sistem pendidikan tinggi (Marmolejo, World Bank, 2017).

Seiring dengan perkembangan ini, intensnya komunikasi antar bangsa menjadi sebuah kelaziman, dan dapat dipastikan bahwa interaksi antar budaya menggunakan bahasa tertentu menjadi hal yang tidak dapat dihindari. Menurut Liu (2009:122) komunikasi lintas budaya merupakan komunikasi yang dilakukan orang-orang yang berasal dari latar belakang budaya yang berbeda.

Ketika berinteraksi dengan orang yang berasal dari lingkungan budaya berbeda, diperlukan sikap toleransi, rasa saling memahami, saling menghargai dan berpikiran terbuka.

Dengan demikian, dalam konteks pembelajaran bahasa asing, seorang pendidik bahasa sangat perlu untuk memiliki pengetahuan lintas budaya yang mencakupi pemahaman terhadap kebudayaan, adat istiadat dan kebiasaan bangsa yang menggunakan bahasa yang diajarkannya, serta pemahaman terhadap kebudayaan, adat istiadat dan kebiasaan dari siswa yang sedang mempelajari bahasa asing tersebut.

Tulisan ini akan membahas mengenai pentingnya pemahaman lintas budaya bagi seorang pendidik bahasa Mandarin, materi-materi budaya yang perlu dikuasai pendidik bahasa 
Mandarin, serta pemetaan kurikulum pengetahuan kebudayaan pada prodi kependidikan bahasa Mandarin di Indonesia.

\section{B. Pembahasan}

\section{Pemahaman Lintas Budaya dalam Pembelajaran Bahasa Asing}

Mengutip Chaistain (dalam Prasetyaningtyas, 2017), pengajaran budaya dalam pembelajaran bahasa asing diperlukan karena alasan sebagai berikut: (1) kemampuan untuk berinteraksi dengan orang asing tidak hanya bergantung pada keterampilan berbahasa asing, tetapi juga pada pemahaman awal tentang adat kebiasaan dan budaya bahasa tersebut; (2) pemahaman lintas budaya merupakan salah satu tujuan dasar pendidikan dalam masyarakat internasional modern yang saling memiliki ketergantungan; (3) pemelajar asing memiliki minat yang besar terhadap bahasa asing yang dipelajari. Pembelajaran kemampuan berkomunikasi tidak terlepas dari pengetahuan budaya. Sehingga, pembelajaran bahasa sejatinya pun mencakupi pembelajaran budaya atau unsur-unsur budaya (Cheng, 2008:255).

Interaksi intens pada komunikasi era modern saat ini, menuntut pembelajaran bahasa asing harus mempunyai standar tingkat penguasaan sebagai acuan pengukuran kemampuan. Common European Framework of Reference for Languages (CEFR) adalah kerangka acuan umum Eropa untuk pembelajaran bahasa asing. CEFR menjadi kerangka dasar untuk penyusunan silabus, pedoman kurikulum, ujian, buku teks dan lain-lain yang digunakan di Eropa dan sudah diadaptasi di banyak belahan dunia. CEFR selain menjabarkan capaiancapaian pengetahuan berbahasa dan keterampilan berbahasa asing, juga menjelaskan mengenai pengetahuan budaya bahasa target yang harus dikuasai oleh pemelajar.

Menurut CEFR, perbedaan bahasa dan budaya merupakan suatu kekayaan tak ternilai. Pembelajaran bahasa asing perlu menjelaskan pengetahuan budaya, adat istiadat serta kebiasaan sehingga dapat mengubah perbedaan yang sedianya dapat menjadi kesalahpahaman serta jurang komunikasi menjadi rasa saling memahami, toleransi, menghormati identitas dan perbedaan.

Pentingnya pemahaman lintas budaya pada pembelajaran bahasa asing juga tertuang dalam European Profiling Grid (EPG). Kompetensi lintas budaya merupakan salah satu dari 13 kategori kompetensi yang harus dikuasai pendidik bahasa asing, dengan tahapan perkembangan sebagai berikut: 


\section{Tabel 1. Kompetensi Lintas Budaya dalam European Profiling Grid (EPG)}

(Tabel diambil dari The European Profiling Grid, 2013:7)

\begin{tabular}{|c|c|c|c|c|c|}
\hline \multicolumn{2}{|c|}{ Development Phase 1} & \multicolumn{2}{|c|}{ Development Phase 2} & \multicolumn{2}{|c|}{ Development Phase 3} \\
\hline 1.1 & 1.2 & 2.1 & 2.2 & 3.1 & 3.2 \\
\hline $\begin{array}{l}\text { - Understands } \\
\text { that the } \\
\text { relationship } \\
\text { between } \\
\text { language and } \\
\text { culture is an } \\
\text { important } \\
\text { factor in } \\
\text { language } \\
\text { teaching and } \\
\text { learning }\end{array}$ & $\begin{array}{l}\text { - Is learning } \\
\text { about the } \\
\text { relevance of } \\
\text { cultural issues } \\
\text { in teaching } \\
\text { - Can } \\
\text { introduce } \\
\text { learners to } \\
\text { relevant } \\
\text { differences in } \\
\text { cultural } \\
\text { behavior and } \\
\text { traditions } \\
\text { - Can create an } \\
\text { atmosphere of } \\
\text { tolerance and } \\
\text { understanding } \\
\text { in classes } \\
\text { where there is } \\
\text { social and } \\
\text { cultural } \\
\text { diversity }\end{array}$ & $\begin{array}{l}\text {-Understands } \\
\text { and is able } \\
\text { to take } \\
\text { account of } \\
\text { relevant } \\
\text { stereotypical } \\
\text { views } \\
\text { - Can use } \\
\text { own } \\
\text { awareness to } \\
\text { expand } \\
\text { students' } \\
\text { knowledge } \\
\text { of relevant } \\
\text { cultural } \\
\text { behavior, } \\
\text { e.g. } \\
\text { politeness, } \\
\text { body } \\
\text { language } \\
\text { etc. } \\
\text {-Can } \\
\text { recognize } \\
\text { the } \\
\text { importance } \\
\text { of avoiding } \\
\text { intercultural } \\
\text { problems in } \\
\text { the } \\
\text { classroom } \\
\text { and } \\
\text { promotes } \\
\text { inclusively } \\
\text { and mutual } \\
\text { respect }\end{array}$ & $\begin{array}{l}\text { - Can help } \\
\text { learners to } \\
\text { analyse } \\
\text { stereotypical } \\
\text { views and } \\
\text { prejudices } \\
\text { - Can } \\
\text { integrate } \\
\text { into lessons } \\
\text { key areas of } \\
\text { difference in } \\
\text { intercultural } \\
\text { behavior } \\
\text { (e.g. } \\
\text { politeness, } \\
\text { body } \\
\text { language } \\
\text { etc.) } \\
\text { - Can select } \\
\text { materials } \\
\text { that are well } \\
\text { matched to } \\
\text { the cultural } \\
\text { horizon of } \\
\text { learners and } \\
\text { yet extends } \\
\text { this further } \\
\text { using } \\
\text { activities } \\
\text { appropriate } \\
\text { to the group }\end{array}$ & $\begin{array}{l}\text { - Can use web } \\
\text { searches, } \\
\text { projects and } \\
\text { presentations } \\
\text { to expand } \\
\text { own and } \\
\text { learners } \\
\text { understanding } \\
\text { and } \\
\text { appreciation } \\
\text { of } \\
\text { intercultural } \\
\text { issues } \\
\text { - Can develop } \\
\text { learners' } \\
\text { ability to } \\
\text { analyze and } \\
\text { discuss social } \\
\text { and cultural } \\
\text { similarities } \\
\text { and } \\
\text { differences } \\
\text { - Can } \\
\text { anticipate and } \\
\text { manage } \\
\text { effectively } \\
\text { areas of } \\
\text { intercultural } \\
\text { sensitivity }\end{array}$ & $\begin{array}{l}\text { - Can use } \\
\text { her/his } \\
\text { extensive } \\
\text { knowledge of } \\
\text { intercultural } \\
\text { issues when } \\
\text { this is } \\
\text { appropriate to } \\
\text { assist less } \\
\text { experienced } \\
\text { colleagues } \\
\text { - Can develop } \\
\text { colleagues' } \\
\text { ability to deal } \\
\text { with cultural } \\
\text { issues, } \\
\text { suggesting } \\
\text { techniques to } \\
\text { defuse } \\
\text { disagreements } \\
\text { and critical } \\
\text { incidents if } \\
\text { they arise } \\
\text { - Can create } \\
\text { activities, } \\
\text { tasks and } \\
\text { materials for } \\
\text { own and } \\
\text { colleagues' } \\
\text { use and can } \\
\text { seek feedback } \\
\text { on these }\end{array}$ \\
\hline
\end{tabular}

Tabel di atas menjabarkan dengan detail mengenai kompetensi pendidik bahasa asing dalam memahami budaya bahasa target.Baik CEFR dan EPG merupakan standar acuan yang digunakan dalam pembelajaran bahasa asing di Fakultas Bahasa dan Seni UNJ.

\section{Materi-materi Budaya yang Perlu Dikuasai}

Andriani (2016) memaparkan, dengan memiliki pengetahuan budaya, komunikasi akan menjadi lebih lancar dan dapat terhindar dari kesalahpahaman yang disebabkan 
ketidakmengertian akan perbedaan budaya. Dengan demikian, dalam konteks pembelajaran bahasa Mandarin, pengetahuan budaya Cina merupakan hal yang patut diperhatikan.

Menurut Bi (dalam Prasetyaningtyas, 2017), materi budaya yang harus dikuasai pemelajar bahasa Mandarin dapat dipelajari melalui 2 jenis kegiatan berkomunikasi: (1) komunikasi lintas budaya verbal, (2) komunikasi lintas budaya non verbal. Pada jenis kegiatan komunikasi yang pertama yaitu komunikasi lintas budaya verbal, materi budaya dipelajari mencakupi bunyi bahasa, bentuk kata atau peribahasa. Pada jenis kegiatan komunikasi yang ke dua yaitu komunikasi lintas budaya non verbal, materi budaya yang dipelajari mencakupi: isyarat tangan, sikap/tingkah laku, pakaian, pandangan mata, ekspresi perasaan, jarak, sentuhan dan volume suara.

Cheng (2008:240) menyatakan pemelajar asing yang mempelajari bahasa Mandarin, baik belajar langsung di Cina maupun belajar di negara mereka masing-masing, tetap harus memahami seluk beluk tentang Cina. Dalam proses memahami pengetahuan tentang Cina tersebut, selain mempelajari bahasanya tentu harus memahami budayanya.

Dalam penentuan materi-materi budaya yang perlu dikuasai pemelajar bahasa Mandarin, Confusius Institute Headquarter/ Hanban pada tahun 2008 telah merincinya dalam Kurikulum Pendidikan Bahasa Mandarin. Materi yang dimaksud terdiri atas 19 butir berikut: (1) etika dan kebiasaan, (2) panggilan kekerabatan, (3) simbol binatang/shio, (4) musik, tari dan lukisan, (5) olahraga, (6) alat transportasi, (7) media massa, (8) geografi, (9) arsitektur, (10) pendidikan, (11) opera, (12) hari raya, (13) iklim, (14) sejarah, (15) fenomena Cina masa kini, (16) sastra, (17) wisata, (18) makanan, dan (19) produk khas Cina.

Prasetyaningtyas (2017) menyatakan pembelajaran bahasa Mandarin berbasis komunikasi lintas budaya dimulai dengan memahami tata cara pemberian salam, permintaan maaf, permohonan izin, dan lainnya. Pada tahapan berikutnya, mulai diperkenalkan kosakata sebagai sarana unuk memperkenalkan inti serta konsep budaya Cina. Pembelajaran dengan pengenalan dan pembiasaan cara berkomunikasi berbasis lintas budaya pada akhirnya dapat menumbuhkan rasa bahasa yang sesuai dengan penutur asli saat berkomunikasi.

\section{Pengetahuan Budaya Cina pada Kurikulum Prodi Kependidikan Bahasa Mandarin}

Pada Forum FBSI Prodi Seni, Prodi Bahasa Daerah dan Prodi Bahasa Asing LPTK seIndonesia di Yogyakarta, 4-5 Mei 2018, prodi-prodi kependidikan bahasa Mandarin melakukan pembahasan mengenai struktur kurikulum. Berdasarkan data sebaran mata kuliah pada struktur 
kurikulum yang saat ini berlaku di 4 prodi kependidikan bahasa Mandarin (eks IKIP) yang hadir pada forum tersebut, terdapat mata kuliah yang terkait dengan kebudayaan Cina. Lebih rinci dapat dilihat pada tabel berikut:

Tabel 2. Sebaran Mata Kuliah Terkait Kebudayaan Cina pada Prodi Kependidikan Bahasa Mandarin di Indonesia

\begin{tabular}{|c|c|c|c|c|}
\hline $\begin{array}{l}\text { Universitas } \\
\text { Semester ke- }\end{array}$ & $\begin{array}{c}\text { Universitas } \\
\text { Negeri Semarang }\end{array}$ & $\begin{array}{c}\text { Universitas } \\
\text { Negeri Surabaya }\end{array}$ & $\begin{array}{c}\text { Universitas Negeri } \\
\text { Jakarta }\end{array}$ & $\begin{array}{c}\text { Universitas Negeri } \\
\text { Makassar }\end{array}$ \\
\hline II & - & - & $\begin{array}{l}\text { Pengantar Sejarah Cina } \\
\text { (2 sks) }\end{array}$ & - \\
\hline III & - & 2 & $\begin{array}{l}\text { Pengantar Kebudayaan } \\
\text { dan Kesusastraan Cina } \\
(2 \text { sks) }\end{array}$ & 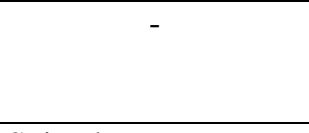 \\
\hline \multirow[t]{2}{*}{$\mathbf{V}$} & - & Sinologi (2 sks) & - & $\begin{array}{l}\text { Sejarah Kesusastraan } \\
\text { Tiongkok I (4 sks) }\end{array}$ \\
\hline & - & $\begin{array}{lr}\text { Teori } & \text { dan } \\
\text { Apresiasi } \quad \text { Sastra } \\
\text { China (3 sks) }\end{array}$ & - & - \\
\hline \multirow[t]{3}{*}{ VI } & $\begin{array}{l}\text { Zhongguo } \\
\text { Wenhua* (2 sks) }\end{array}$ & - & $\begin{array}{ll}\text { Pemahaman } & \text { Lintas } \\
\text { Budaya (2 sks) } & \end{array}$ & $\begin{array}{l}\text { Sejarah Kesusastraan } \\
\text { Tiongkok II* (2 sks) }\end{array}$ \\
\hline & $\begin{array}{lrl}\text { Tang } & \text { Shi } & \text { Song } \\
\mathrm{Ci}^{*}(2 \mathrm{sks}) & \\
\end{array}$ & - & - & - \\
\hline & $\begin{array}{l}\text { Zhongguo Lishi (2 } \\
\text { sks) }\end{array}$ & - & - & - \\
\hline VIII & - & 2 & $\begin{array}{l}\text { Budaya Kesantunan } \\
\text { Cina* (2 sks) }\end{array}$ & - \\
\hline \multirow{2}{*}{ Total sks } & 2 sks wajib & 5 sks wajib & 6 sks wajib & 4 sks wajib \\
\hline & 4 sks pilihan & - & 2 sks pilihan & 2 sks pilihan \\
\hline
\end{tabular}

Keterangan tabel:

*Mata kuliah pilihan

Zhongguo Wenhua

Tang Shi Song Ci

= Kebudayaan Cina

Zhongguo Lishi

$=$ Puisi Dinasti Tang

$=$ Sejarah Cina

Tabel di atas menjelaskan bahwa prodi kependidikan bahasa Mandarin di Indonesia telah memiliki sejumlah mata kuliah terkait kebudayaan Cina dalam kurikulumnya. Namun demikian, dengan melihat nama mata kuliah yang terkait budaya Cina tersebut, maka dapat terlihat bahwa fokus masing-masing prodi terhadap materi budaya Cina sangat beragam. Terlihat pula perbedaan pada bobot SKS, dan perbedaan sebaran mata kuliah semester. Berdasarkan tabel di atas, dengan memperhitungkan sks minimal kelulusan yaitu 144 sks, porsi mata kuliah terkait pengetahuan kebudayaan Cina dalam struktur kurikulum di masing-masing prodi rata-rata berada pada kisaran 3,47\% hingga 5,55\%.

Selain secara khusus menjadi materi mata kuliah yang terkait dengan kebudayaan Cina, pembelajaran pengetahuan kebudayaan Cina juga dileburkan kedalam mata kuliah keterampilan berbahasa Mandarin. Hal ini dikarenakan: (1) budaya dan bahasa tidak 
terpisahkan sehingga pembelajaran pengetahuan kebudayaan dapat diajarkan bersamaan dengan keterampilan berbahasa secara tematis, (2) buku-buku teks keterampilan berbahasa Mandarin yang digunakan mengandung muatan unsur budaya Cina.

Mengenai buku teks, pada tahun 2016 Andriani melakukan penelitian berupa pemetaan muatan budaya Cina dalam buku teks keterampilan berbahasa Mandarin Hanyu Jiaocheng yang merupakan buku yang sangat umum digunakan untuk pembelajaran bahasa Mandarin di tingkat perguruan tinggi. Hasil penelitian menunjukkan, seluruh unsur budaya universal (100\%) dapat dijumpai dalam buku teks Hanyu Jiaocheng berupa teks bacaan dan ilustrasi.

Dalam teks bacaan, unsur dan wujud budaya yang muncul yaitu: (1) unsur peralatan dan perlengkapan hidup, dengan wujud peninggalan bersejarah, rumah tradisional, sekolah/universitas, makanan dan minuman khas, peralatan makan dan minum, obat-obatan, karya seni (kaligrafi), dan perlengkapan opera, serta payung dan lampion; (2) unsur sistem kemasyarakatan, dengan wujud kota terlarang, sistem pemberian nama, satuan berat, mata uang dan satuannya, hari raya, dan zodiak (shio); (3) unsur bahasa, dengan wujud sistem pemberian nama, sinifikasi nama non Cina, pembagian waktu, serta sistem penyebutan dan penulisan waktu (tahun, bulan, tanggal); (4) unsur kesenian, dengan wujud peninggalan bersejarah, rumah tradisional, opera Beijing, kaligrafi dan bela diri; (5) unsur sistem pengetahuan, dengan wujud peninggalan bersejarah, rumah tradisional, peralatan makan dan minum, makanan dan minuman khas Cina, mata uang dan satuannya, satuan berat, obat-obatan, sinifikasi nama non Cina, sistem pembagian waktu, zodiak (shio), opera, kaligrafi dan bela diri; (6) unsur religi/kepercayaan, dengan wujud kegiatan hari raya; mata pencaharian hidup dan sistem ekonomi, dengan wujud kota terlarang, satuan berat, mata uang dan satuannya.

Dalam ilustrasi, hanya ada 6 unsur budaya yang ditemukan yaitu: (1) unsur peralatan dan perlengkapan hidup, dengan wujud peninggalan bersejarah, rumah tradisional, peralatan makan dan minum, obat-obatan, karya seni (lukisan dan kaligrafi), serta payung dan lampion; (2) unsur sistem kemasyarakatan, dengan wujud kota terlarang, satuan berat, mata uang dan satuannya, dan zodiak (shio); (3) unsur bahasa, dengan wujud bahasa isyarat dengan jari tangan; (4) unsur kesenian, dengan wujud peninggalan bersejarah, kaligrafi, baju khas, lampion, peralatan makan dan minum, seni tari (barongsai), rumah tradisional, dan opera Beijing; (5) unsur sistem pengetahuan, dengan wujud peninggalan bersejarah, rumah tradiosonal, peralatan makan dan minum, makanan dan minuman khas, mata uang dan satuannya, satuan berat, obatobatan, zodiak (shio), opera, kaligrafi, dan bela diri, serta paying dan lampion; (6) Mata 
pencaharian hidup dan sistem ekonomi, dengan wujud kota terlarang, satuan berat, mata uang dan satuannya.

\section{Simpulan}

Pengetahuan budaya diperlukan sebagai sarana mencapai tujuan pembelajaran bahasa Mandarin yaitu berkomunikasi tanpa terjadi hambatan budaya atau kesalahpahaman (Prasetyaningtyas, 2017). Pentingnya pemahaman lintas budaya pada pembelajaran bahasa asing juga terlihat dalam European Profiling Grid (EPG). Dengan demikian kompetensi lintas budaya merupakan salah satu dari kategori kompetensi yang harus dikuasai pendidik bahasa asing.

Penguasaan materi budaya dapat dilakukan melalui 2 jenis kegiatan berkomunikasi: (1) komunikasi lintas budaya verbal, (2) komunikasi lintas budaya non verbal. Confusius Institute Headquarter/Hanban pada tahun 2008 telah merinci materi-materi budaya yang perlu dikuasai pemelajar bahasa Mandarin ke dalam 19 butir, yaitu (1) etika dan kebiasaan, (2) panggilan kekerabatan, (3) simbol binatang/shio, (4) musik, tari dan lukisan, (5) olahraga, (6) alat transportasi, (7) media massa, (8) geografi, (9) arsitektur, (10) pendidikan, (11) opera, (12) hari raya, (13) iklim, (14) sejarah, (15) fenomena Cina masa kini, (16) sastra, (17) wisata, (18) makanan, dan (19) produk khas Cina.

Prodi kependidikan bahasa Mandarin di Indonesia telah merespon tuntutan akan penguasaan pengetahuan budaya Cina yang harus dimiliki pendidik bahasa Mandarin dengan memasukkan mata kuliah terkait kebudayaan Cina. Akan tetapi setiap prodi memiliki perbedaan fokus materi budaya bobot SKS, dan sebaran semester. Selain disampaikan pada mata kuliah yang terkait dengan kebudayaan Cina, pembelajaran pengetahuan kebudayaan juga telah dileburkan ke dalam mata kuliah keterampilan berbahasa Mandarin. Hal ini dikarenakan karakteristik budaya dan bahasa yang tidak terpisahkan, serta buku-buku teks keterampilan berbahasa Mandarin yang digunakan telah mengandung muatan unsur budaya Cina. 


\section{Daftar Pustaka}

Andriani, Susi dan Jihan Maharani. 2016. Pemetaan Muatan Budaya Cina dalam Buku Teks Keterampilan Bahasa Mandarin untuk Keperluan Pengembangan Materi Ajar Mata Kuliah Pengantar Kebudayaan Cina. Laporan Penelitian Fakultas Bahasa dan Seni. Chaer, Abdul. 2010. Sosiolinguistik. Jakarta: Rineka Cipta.

EAQUALS. 2013. The European Profiling Grid.

Prasetyaningtyas, Hudiyekti. 2017. "Pembelajaran Bahasa Mandarin Berbasis Komunikasi Lintas Budaya” dalam Prosiding Seminar Nasional Literasi Bahasa dan Sastra ke-2. Fakultas Bahasa dan Seni, Universitas Negeri Semanrang.

Schwab, Klaus. 2016. The Fourth Industrial Revolutuon. New York: Crown Business.

程堂, 2008, 对外汉语教学目的、原则、方法, 北京: 北京语言大学出版社。

国家汉办, 2008 , 《国家汉语教学通用课程大纲》, 北京: 外语教学与研究出版社。 刘珣, 2009, 对外汉语教学引导, 北京: 北京语言大学出版社。 